\title{
Correction to: Prenatal attachment: Using measurement invariance to test the validity of comparisons across eight culturally diverse countries
}

\author{
Sarah Foley ${ }^{1}$. Claire Hughes ${ }^{1}$ - Aja Louise Murray ${ }^{2} \cdot$ Adriana Baban $^{3}$ - Asvini D. Fernando ${ }^{4}$. Bernadette Madrid ${ }^{5}$. \\ Joseph Osafo ${ }^{6}$. Siham Sikander ${ }^{7}$. Fahad Abbasi ${ }^{7}$. Susan Walker ${ }^{8}$. Thang Vo Van ${ }^{9}$. Bao-Yen Luong-Thanh ${ }^{9}$. \\ Mark Tomlinson $^{10,11}$. Pasco Fearon ${ }^{12}$. Catherine L. Ward ${ }^{13}$. Sara Valdebenito ${ }^{14}$. Manuel Eisner ${ }^{14}$
}

(c) Crown 2021

\section{Correction to: Archives of Women's Mental Health https://doi.org/10.1007/s00737-021-01105-8}

The names of the authors were incorrect.

1. Bao-Yen Luong-Thanh appears twice - please remove Yen Lương Thanh Bảo

2. Replace Yen Lương Thanh Bảo with Thang Van Vo (see below).

Open Access This article is licensed under a Creative Commons Attribution 4.0 International License, which permits use, sharing, adaptation, distribution and reproduction in any medium or format, as long as you give appropriate credit to the original author(s) and the source,

The original article can be found online at https://doi.org/10.1007/ s00737-021-01105-8.

Sarah Foley

Sarah.Foley@ed.ac.uk

1 Centre for Family Research, University of Cambridge, Cambridge, UK

2 Department of Psychology, University of Edinburgh, Edinburgh, UK

3 Department of Psychology, Babes-Bolyai University, Cluj-Napoca, Romania

4 Department of Paediatrics, Faculty of Medicine, University of Kelaniya, Colombo, Sri Lanka

5 Child Protection Unit, University of the Philippines, Manila, Philippines

6 Department of Psychology, University of Ghana, Legon, Accra, Ghana

7 Health Services Academy, Islamabad, Pakistan

8 Caribbean Institute for Health Research, The University of the West Indies, Kingston, Jamaica provide a link to the Creative Commons licence, and indicate if changes were made. The images or other third party material in this article are included in the article's Creative Commons licence, unless indicated otherwise in a credit line to the material. If material is not included in the article's Creative Commons licence and your intended use is not permitted by statutory regulation or exceeds the permitted use, you will need to obtain permission directly from the copyright holder. To view a copy of this licence, visit http://creativecommons.org/licenses/by/4.0/.

Publisher's Note Springer Nature remains neutral with regard to jurisdictional claims in published maps and institutional affiliations.
9 Institute for Community Health Research, Faculty of Public Health, Hue University of Medicine and Pharmacy, Hue University, Hue, Vietnam

10 Department of Psychology, Stellenbosch University, Stellenbosch, South African Institute for Life Course Health Research, Department of Global Health, Stellenbosch University, Cape Town, South Africa

11 School of Nursing and Midwifery, Queens University, Belfast, UK

12 Research Department of Clinical, Educational and Health Psychology, University College London, London, UK

13 Department of Psychology, University of Cape Town, Cape Town, South Africa

14 Institute of Criminology, University of Cambridge, Cambridge, UK 